\title{
Smarter through Social Protection? Evaluating the impact of Ethiopia's safety-net on child cognitive abilities.
}

(Word Counts 5,945)

\begin{abstract}
We provide new estimates of the impact of Ethiopia's Productive Safety Net Programme (PSNP) in Ethiopia on child cognitive achievement in the medium term. The programme is the second largest in Africa, and has been rolled out to almost 10 million beneficiaries since 2005. We exploit four rounds of the Young Lives panel data spanning 2002-2013. We find a small but significant effect of the programme on cognitive achievement as measured by numeracy skills. We examine heterogeneity of impacts via "graduation" from the scheme, and find a positive effect on children in households that graduated just before 2013, but none for children in households that remain in the programme.
\end{abstract}

Keywords: Ethiopia, social protection, children, cognitive development.

JEL codes: I38, O22 


\section{Introduction}

Can anti-poverty programmes which also contain a work requirement impact positively on children's futures? Creating evidence on the effectiveness of cash transfers, both conditional and unconditional, has become a huge area of research in the past ten years, and such programmes are now seen as a key pillar of the anti-poverty effort. In many countries, most notably India, South Africa and Ethiopia, workfare (or cash/food for work) programmes also comprise an integral component of the social protection strategy (Subbarao et al., 2012). Baird et al. (2014) review the impact of both conditional and unconditional cash transfers (CCTs and UCTs respectively), and find overall evidence that both of these do have a positive impact on enrollment and attendance at school. However, the authors find little evidence that cash transfers matter for learning outcomes, such as performance on cognitive achievement tests. The evidence on workfare programmes is rather more sparce. Mani et al. (2014) found India's flagship rural employment programme to have strong positive effects on grade progression and a number of cognitive skills tests, however Shah and Steinberg (2015) find both a negative effect on school enrollment and reduced test scores, for older children.

This paper contributes to filling the evidence gap on social protection and learning, using information on child cognitive achievement in Ethiopia, combined with information on participation in a national social protection scheme. The Productive Safety Net Programme (PSNP) was introduced in 2005, and is a broad social safety net with a workfare emphasis, implemented at scale in a low-income context. There has been considerable policy interest in the impact of the programme, given that it is the largest in sub-Saharan Africa outside of South Africa. Several evaluations have found that the programme has been well targeted overall, and that it had positive impacts on several dimensions of rural household wellbeing including an increase in households' reported months of food security per year (the official outcome target of the programme). 
While the impact of the PSNP on poverty is becoming better established, the work requirement of the programme means that there could be an ambiguous effect on child outcomes such as cognitive achievement, through its impact on time-use of adults and children. In a situation where children substitute for adults on activities, e.g. inside the family farm or enterprise, or domestic tasks, this substitution effect could outweigh the (positive) income effect of the programme, leading to a reduction of children's time in school or studying. Also, if the time spent with parents has a positive impact on learning outcomes, an increase in parental time spent outside at work could have adverse effects.

This paper is structured as follows: the next section situates the paper in the literature, and gives a brief outline of the PSNP programme structure and background; section three lays out the conceptual framework and discusses the estimation strategy; section four presents the data used and describes the main characteristics of the PSNP beneficiaries and of the control group; section five presents the main empirical results and discusses the findings; and the final section concludes.

\section{Background and related literature}

\subsection{Impacts of social programmes on child outcomes}

The supportive evidence body is now quite convincing that investments in child human capital (and conversely, shocks to these investments) can have a significant impact on human capital attainments and achievements as adults (Alderman et al., 2006; Hoddinott et al., 2008; Dercon and Porter, 2014). Although the importance of early child development is well appreciated worldwide, attention is only beginning to be given to the extent to which social protection has the potential to impact child human capital outcomes, both through protection and promotion. We briefly review the most relevant literature. Thus far, most studies on child cognitive outcomes and social protection have 
been of conditional cash transfer programmes that have been rolled out initially in Latin America (Gertler, 2004; Fernald et al., 2008a; Barham et al., 2013).

Fernald et al. (2008b) show that Mexico's flagship conditional cash transfer programme, Oportunidades, is associated with a significant improvement in cognitive achievement as measured by vocabulary test, short and long-term memory tests (for children over 36 months) Macours et al. (2012) find significant improvements in cognitive development of children exposed to a CCT in Nicaragua nine months after the program began. The authors hypothesise that the impacts are the result from the cash component combined with the conditionalities imposed on families, which they show through behavioural changes such as an increased expenditures on critical inputs into child development.

Paxson and Schady (2010) show that an unconditional cash transfer programme in Ecuador improved cognitive outcomes for children, especially for the poorest children in the sample, for girls and for those with better-educated mothers. The authors show suggestive evidence that the channel of impact to cognitive development in this case operates through higher intake of nutrition and deworming, rather than through improved parenting or visits to health clinics, or maternal mental health. Beneficiaries of an unconditional cash transfer in Malawi (Baird et al., 2011) showed a significant increase in school enrollment. The study also found a significant decrease in teenage pregnancy and fertility for the sample of adolescent girls. However, it did not find detectable improvements in school attendance or their test scores.

Evidence on the largest public works program in the world, India's Mahatma Gandhi National Rural Employment Guarantee Scheme (MGNREGS), has shown mixed results for child outcomes. Mani et al. (2014) find MGNREGS to have strong positive effects on grade progression and a number of cognitive skills tests (reading comprehension test

\footnotetext{
${ }^{1}$ Vocabulary was measured by the Peabody Picture Vocabulary Test as administered by the YL survey, and memory tests from Spanish language version of the revised Woodcock-Muoz test.
} 
scores, math test scores and Peabody Picture Vocabulary Test scores). Further, they found that the effect of the programme increases over time. However, Shah and Steinberg (2015) find that children in participant households had lower enrollment, and lower cognitive achievement. We know of no other studies on the effects of public works programmes on child cognitive outcomes.

\subsection{PSNP and food aid in Ethiopia}

The PSNP was introduced in Ethiopia in 2005 as a national programme replacing previous piecemeal responses to drought. Ethiopia has a history chronic drought and food insecurity in rural areas, and many households were reliant on unpredictable emergency food aid. The innovations in the approach were a) designed as a partnership between the Government of Ethiopia and a large number of donors (The World Bank, United Nations agencies and bilateral donors); and b) to provide predictable assistance. The objective of the PSNP is 'to provide transfers to the food insecure population in chronically food insecure woredas (districts) in a way that prevents asset depletion at the household level and creates assets at the community level' as well as to bridge the food gap that arises when, for these households, food production and other sources of income are insufficient given the food needs (Ministry of Agriculture and Rural Development, 2004).

The PSNP transfers to poor households mainly (80\%) through public works, with less than a fifth of households receiving direct support, in absence of adult labour. In 2013, the year of our study, the PSNP supported 7.2 million people (roughly $10 \%$ of the national population) in 290 chronically food insecure woredas in 8 of the country's 10 regions. Phase 3 from 2010-2015 attempted to improve timeliness and predictability of transfers, strengthen public works and accountability, as well as the Household Asset Building Program (HABP, see Holmemo (2014)). In September 2014, Phase 4 of the PSNP was announced, to last until 2020:2

\footnotetext{
${ }^{2}$ http://www.worldbank.org/en/news/loans-credits/2014/09/30/ethiopia-productive-safety-nets-
} 
The goal is that the PSNP should improve household food security up to the point that it graduates (leaves the programme). This is defined as : "A household has graduated when, in the absence of receiving PSNP transfers, it can meet its food needs for all 12 months and is able to withstand modest shocks." Since 2005, approximately 500,000 beneficiaries have been graduated from the PSNP (Hoddinott, 2014). Nonrandom programme placement of the PSNP means it has been historically targeted towards food-insecure households. This leads to challenges in finding a convincing identification strategy when assessing the impact of the programme.

PSNP has overall been found effective in improving household level measures of food security and consumption (Yablonski, 2007; Berhane et al., 2014). In Berhane et al. (2014), beneficiaries who had received the programme for at least three years experienced improvements in their food security. The comparison group of those who received PSNP for only one year showed no impact of being in the scheme compared to non-participants. Other studies have found that households enrolled in the PSNP avoided selling assets in situations of food shortages, and 36\% avoided using savings to buy food (Alderman and Yemtsov, 2012). Participant households are also more likely to consume the required 1,800 calories per day than non-beneficiaries (Save the Children UK, 2008).

The limited evidence suggests that the PSNP has had both intended and unintended outcomes for children. Porter and Goyal (2014) find that by 2009, the PSNP had a positive impact on child nutrition. A study for USAID (2012) finds statistically significant evidence of increased number of meals consumed by children from households in public works. However, Tafere and Woldehanna (2012) find more mixed effects with regard to child time use. The authors show that the programme increased time spent on both paid and unpaid work. Conversely, Emirie et al. (2009) find a positive impact of public works on school enrollment, which they considered was due to the increased income. Camfield (2014) finds considerable evidence of girls working in the PSNP programme, or increasing project-4, last accessed 24th Aug 2016. 
their household chores in response to caregivers' participation in the programme.

We would therefore expect participation in the PSNP to have a positive effect on the cognitive outcomes of participant household children if the improvement in nutrition also translates into improved cognition (Behrman and Rosenzweig, 1996). However, if labour supply demands on adults change children's time use (Woldehanna, 2010), there may be adverse time-use effects and a negative effect on child's cognition. Therefore, we investigate whether PSNP improved cognitive outcomes given the work requirement and other risks faced by households in the years up to 2013 (the latest survey round).

\section{$3 \quad$ Methodology}

\subsection{Production of Child cognitive achievement}

Our estimates of the impact of the safety net on child achievement are nested in a theoretical framework that reflects the literature on the production of skills in children, drawing particularly on the works of Todd and Wolpin 2003, 2007), Cunha and Heckman 2007, 2008) and Andrabi et al. (2011). These papers provide a theoretical basis for the understanding of the determinants on child development, as well as the assumptions that are implicit in empirical specifications that attempt to estimate them.

The production of child skills, known also as human capital, or achievement, is modelled as a function of household and school inputs, as well as the child's innate abilities and inputs (e.g. time spent on educational activities).

A general production function for achievement is shown below:

$$
A_{i k a}=A_{a}\left(A_{i k a-1}, A_{i k a-2 \ldots .}, X_{i k \ldots}, X_{i k-1} \ldots X_{i k-2} \ldots\right)
$$

Where $A_{i k a}$, the achievement or skill of child $i$ in household $k$ at age $a$ is a function of $X_{i k}$, generalised to contain all inputs (contemporaneous and past), at child, household 
and school/community level as well as an initial endowment, or ability $\left(\mu_{i k 0}\right)$ vector of child-specific characteristics such as sex, age, inherited healthiness/intellectual potential. Not all of these are observable. We note that this production function for learning is a structural relation. Todd and Wolpin (2003, 2007) note that under the assumption that effect of inputs (both observed and unobserved) as well as that of initial ability decline geometrically over time, then a "lag Value added" model can be specified, using only the immediate lag of achievement serving as a proxy for all previous inputs, and ability.

$$
A_{i k a}=X_{i k a} \alpha+\gamma A_{i k, a-1}+e_{i k a}
$$

The lagged "value added" model specified in equation 2 has slightly less restrictive assumptions than a first difference model. Das et al. (2013) argue that caution is needed when interpreting cash grants received as a parameter in an education production function. This is a pertinent point for our research question, as money received from PSNP comes with a time-use implication.

In this spirit, we follow Glewwe and Muralidharan (2016) separating the production function into a vector comprising

$$
A=f(S, Q, C, H, I)
$$

Where: $S=$ years of schooling; $Q=$ vector of quality (School and teacher characteristics); $C=$ child characteristics (ability, motivation); $H=$ household characteristics (financial, time constraints, parental education); $I=$ Inputs at household level (school attendance, encouragement to do homework etc).

Parents maximise household utility, $U=($.$) , where U$ will contain consumption and leisure of the adults, as well as consumption and schooling of the children. The constraints to maximisation are the production function of achievement, the rate of return to achievement and other income constraints (household labour requirements, 
credit constraints) as well as the price of schooling, $P$. Parents will therefore make decisions on inputs, and on school attendance based on this framework.

If $C$ and $H$ are exogenous (given) and assuming that there is only one local school and that parents are unable to influence the school (i.e. assume $Q$ and $P$ to be fixed), parents choose $S$ and $I$ as part of the utility maximisation exercise. Glewwe and Muralidharan (2016) show that $S$ and $I$ can then be written in terms of exogenous variables:

$$
\begin{aligned}
& S=f(Q, C, H, P) \\
& I=g(Q, C, H, P)
\end{aligned}
$$

Insert 4 and 5 into 3 gives us the reduced form equation for achievement which can be considered as causal, but not a production function

$$
A=h(Q, C, H, P)
$$

since it reflects prices, preferences, and potentially behavioural responses to any policy change. PSNP would affect $H$ as it increases household income.

Finally, Fiorini and Keane (2014) outline the importance of incorporating the full time - use vector as part of the child-level inputs into cognitive achievement. We do this as a robustness check. It allows us to understand the importance of children's working/school/study time in the Ethiopian context, given that it is a possible channel through which the programme may affect cognitive development of children. However we note that our main estimates are of the full policy effect of the programme on cognitive achievement, taking into consideration all ex-post household responses. 


\section{$3.2 \quad$ Empirical strategy}

Our empirical strategy is based on the literature on cognitive ability summarised in section 3.1. Our estimating equation as noted above is a conditional demand function for child cognitive ability (Glewwe and Miguel, 2007; Glewwe and Muralidharan, 2016).

The empirical analogue to equation 6 above is expressed in levels as:

$$
A_{i k a}=\alpha+\beta_{1} A_{i k a-1}+\beta_{2} P S N P_{k a}+\beta_{3} K_{k a}+\beta_{4} Z_{v a}+\delta_{1} \mu_{i}+\delta_{2} \nu_{k}+\delta_{3} \lambda_{v}+\epsilon_{i a}
$$

Lagged achievement enters directly, $A_{i k a-1} . K_{k a}$ and $Z_{v a}$ are vectors of contemporaneous time-varying observable household and community characteristics. $\mu_{i}, \nu_{k}$ and $\lambda_{v}$ are child, household and community (unobservable) fixed effects respectively. All of these are by definition time invariant. The treatment variable PSNP is time-varying and binary, equals to one if any member of the household has participated in PSNP in the three years before the survey and zero otherwise.

The impact of the programme on achievement is $\beta_{2}$, and the long term impact of the programme is then equal to $\beta_{2} /\left(1-\beta_{1}\right)$ (Andrabi et al., 2011). The framework outlined in the literature review showed that the inclusion of $A_{i k a-1}$ is crucial for the estimation of a) the dynamics of the conditional demand function and relatedly b) the long-term impact of any intervention in time $t$. To the extent that $A_{i k a-1}$ captures unobservable child, household and community characteristics that may affect programme placement, this allays concerns about the non-random nature of the PSNP.

\section{Data}

We use the Young Lives study panel data from Ethiopia, a longitudinal household data set conducted over four waves. The first survey took place in 2002 with three further rounds of data collection in 2006/7, 2009/10 and 2013/14. The younger cohort (1,999 
children) of the study were aged 6 to 18 months in 2002, and the older cohort were aged 7-8 years. Overall the attrition rate is about 2.2 percent for the $2001 / 2003$ cohort and 8.4 percent for the 1994/95 cohort since the start of the study. In the present analysis, we use the younger cohort data. The dataset comprises children from 20 sentinel sites in the states of Amhara, Oromia, the Southern Nations, Nationalities and Peoples Region (SNNP), Tigray, and Addis Ababa. These were purposively sampled to represent the different regions in Ethiopia with a pro-poor focus. Households within sites were chosen randomly among those that had children who were born in the stipulated year. Importantly, in 2013 PSNP was operating in 14 of these sites with 398 out of the 1873 households (21.3\% of the sample) being active beneficiaries of the programme. The coverage of the program was highest in rural areas (349 out of 398 total beneficiaries in 2013) where the PSNP was operating in 11 of the Young Lives sites.

In all rounds, three main questionnaires were administered to capture various characteristics that are expected to influence the status of the child: a child questionnaire with data on child health, anthropometrics and individual characteristics; a household questionnaire including data on caregiver background, livelihood, household composition, socio-economic status, shocks; and a community questionnaire containing information on demographic, geographic and environmental characteristics, social environment, infrastructure, the economy, health and education.

Households were asked whether they had received payments from public works or direct support within the PSNP framework in 2006, 2009 and 2013. They were also asked the details of which years they were enrolled in the PSNP and how much (cash or in-kind payment) they had received in the past 12 months. They were also asked if they had to their knowledge been shortlisted for the programme or whether they had graduated from the programme, as well as their perceptions of how fair enrollment into PSNP had been.

Our outcome variables for cognitive achievement are the Peabody Picture Vocabulary 
Test (PPVT), a widely-used test of receptive vocabulary Dunn and Dunn (1997), and a mathematics test that was developed by the Young Lives survey team for the purposes of the survey, and is adapted to be appropriate for each round of the survey Cueto et al. (2009); Cueto and Leon (2012) . We standardise the scores by age in order to create a zscore, allowing comparison across years, and to implement the "value added" approach. The PPVT score used in this paper is constructed using Item Response Theory (IRT) models which are commonly used in international assessments such as PISA and TIMSS (see Leon and Singh (2017) for further details).

\subsection{Treatment and control groups}

Table 1 reports information on some basic characteristics of the regression sample measured in round 4 where the surveyed children were 12 years old on average. The regression sample includes only those children observed across all the four rounds of data collection (dropping 133 children) and living in rural areas (dropping 613 children) since the PSNP is a rural programme. We also dropped children living in households which only started receiving the PSNP in 2012, just before the final round of data collection (dropping 108 children). We define households as treated if they answered yes to the question on PSNP participation (either food or cash for work, or direct transfers of food or work). Figure 1 shows the timing of the four survey rounds as well as the introduction of the PSNP and subsequent rollout. Table 2 shows the number of beneficiaries in each year of the survey. In our sample, about 15\% of the households received PSNP in 2009 but graduated from the programme by 2012 and about $26 \%$ were still benefiting from the programme in 2012. The remaining households (about 59\%) never received PSNP. We consider these households as a "broad control group".

Identification of the treatment effect in any PSNP study is complicated by the fact that the programmme was not randomly allocated. Table 3 compare the group of PSNP 
beneficiaries to the control group at baseline when the child was 5 years old. It suggests, as expected, that the control group tends to be richer as measured by the wealth index and consumption, and more educated, than PSNP beneficiaries at baseline. Also children from those household spend on average more time in school and studying than children from PSNP beneficiary households, and have lower test scores and height-forage. Comparing the PSNP-treated households with non-treated as such would likely bias the impact downwards, as those who never received PSNP are presumably different.

For this reason we construct a "more restricted" comparison group arguably more comparable to the PSNP beneficiaries households. In this we include only 1) those who received any kind of government programme (food for work, cash for work, food aid) in 2006 as the baseline control group since they were in some sense eligible for PSNP, and therefore likely quite similar to eventually treated households; 2) the households who reported in 2009 that they had been shortlisted for PSNP, as we know that whilst community-level shortlists were drawn up, some households did not receive PSNP due to budget allocations not being sufficient from the next level of administration.

Bearing in mind that the PSNP was rolled out in 2005-2006, it is not completely clear that the beneficiaries in 2006 were reporting that they received PSNP, or whether it was food or cash for work from a previous incarnation of the programme, but we presume the latter.

Table 4 compares the baseline characteristics of the beneficiaries with the more restricted comparison group. Here we see that the differences between treatment and comparison are now much less, and with only a few exceptions are not significant in wealth, food expenditure or time use $\mathrm{S}^{3}$

\footnotetext{
${ }^{3} \mathrm{Te}$ working is not different, but time in school/study less, and they are less likely to be in the top tertile of the wealth index. There are still fewer mothers with greater than primary education in the treated group, and the maths z-score at baseline is lower for those children in households that continue to be beneficiaries of the programme in 2013 .
} 


\section{Results}

Table 5 and table 6 shows the main results, respectively for the math test and for PPVT. In table 5 the standardized score of the math test measured in 2013 at age 12 is the dependent variable, and the lag of maths achievement is measured in 2009, at age 8 . We assume that the lag achievement captures investments up to age 8, as well as innate ability and other unobserved household and child characteristics. We include community fixed-effects also to capture unobservable community effects that may for example affect PSNP delivery and school quality.

The results using the broad control group show some impacts of the PSNP program on cognitive achievement (column 1-3). There is no average effect of the programme (column 1). However, the results for maths are significant for the group of children in households that graduated from PSNP just before the survey (in 2012, approximately) (column 2 and 3). The impact of approximately 0.13 standard deviations is quite large, and around a third of results from conditional cash transfers of children "treated" at younger ages (Gertler, 2004).

In columns 4-6 we show the results using our more restrictive (and arguably more comparable) definition of the comparison group. Here we do find an average effect of the programme on maths outcomes (column 4). This still appears to be driven by the 2012 graduates (columns 5 and 6). The effect magnitude is higher (between 0.25 and 0.22 standard deviation), approaching that of the CCT results noted above. However, we acknowledge that this sample is much smaller.

The results (both using the broad control group and the restricted one) are robust to the inclusion of ever more stringent controls including education inputs, time use, nutrition, and household expenditure (not reported). Further work needs to establish the mechanism behind this result, for example whether this means that the right households are indeed graduating from the programme, or whether it is selection of households that 
are both more capable and more concerned with child cognitive development.

In table 6 we show the results for PPVT. For this measure of cognition we find no significant effects of the programme at all. This might be related to the specificity (and the timing) of cognitive growth and the influence of schooling on the different set of abilities. It is generally recognized that literacy (reading and vocabulary) is positively related to scores on tests of numeracy and problem solving. Studying the nature and sources of growth across a number of cognitive skills, (Christian et al., 2009) find schooling influences mathematics (and reading recognition,letter recognition, general information, phonemic segmentation skills) but did not appear to shape children's growth in receptive vocabulary (and syllabic segmentation).

In table 7 we examine some of the characteristics of the graduating households to see what might be the drivers of the heterogeneous impact of the programme on mathematics achievement. We see that the graduating households do have significantly higher expenditure on both food and non-food than the households who continue in the programme, suggesting that in this sample, the graduation criteria may be being adhered to. Children also spend significantly longer time in schooling than either the comparison children or those in households that remained in the programme, which is a plausible mechanism of effect, especially for mathematics.

\section{Conclusion}

We have examined the impact of the Productive Safety Net Programme on child cognitive outcomes. The PSNP has been shown to have positive effects on household consumption and food security, but mixed effects on child wellbeing (positive on nutrition, possibly negative on time use). The identification of programme effects is problematic given the non-random placement of PSNP. However, we include baseline cognitive test scores (year 2006) which allows us to estimate a conditional demand function for cognitive 
achievement, including the lagged dependent variable in the spirit of the value-added approach.

Our results, based on information from 2013, when the children were 12 years old, do show a positive impact of the PSNP on child cognitive outcomes, as measured by mathematics test scores. The effect size is smaller in magnitude than those that have been estimated for conditional cash transfers in Latin America. This result is to be expected, given that the programme does have a work requirement for adults, that could lead to substitution of child time into household chores or caring for others, or a diversion of adult attention from children. We do see that the PSNP participant children spend less time studying than non-participants. However, graduates of the programme spent more time in school than either comparison children, or those in households that remained in the programme. The results of course are only for a particular cohort of children and evidence suggests that programme effects are likely to vary with age (Barham et al. 2013). We incorporated the older cohort of the survey (aged 18 years) as well as siblings, but did not find any significant differences in the results for those groups compared to the index children.

The results appear suggestive that the programme can have a positive effect on child cognitive outcomes. 
Disclosure statement: The authors declare that they have no conflict of interest. 


\section{References}

Alderman, H., J. Hoddinott, and B. Kinsey (2006). Long term consequences of early childhood malnutrition. Oxford Economic Papers 58(3), 450-474.

Alderman, H. and R. Yemtsov (2012). Productive role of safety nets: background paper for the World Bank 2012-2022 social protection and labor strategy. Technical report, The World Bank.

Andrabi, T., J. Das, A. I. Khwaja, and T. Zajonc (2011). Do value-added estimates add value? accounting for learning dynamics. American Economic Journal: Applied Economics 3(3), 29-54.

Baird, S., F. H. Ferreira, B. zler, and M. Woolcock (2014). Conditional, unconditional and everything in between: a systematic review of the effects of cash transfer programmes on schooling outcomes. Journal of Development Effectiveness 6(1), 1-43.

Baird, S., C. McIntosh, and B. zler (2011). Cash or condition? evidence from a cash transfer experiment. The Quarterly Journal of Economics.

Barham, T., K. Macours, and J. A. Maluccio (2013). Boys' cognitive skill formation and physical growth: long-term experimental evidence on critical ages for early childhood interventions. American Economic Review 103(3), 467-71.

Behrman, J. and M. Rosenzweig (1996). The impact of health and nutrition on education. World Bank Research Observer 11(1), 23-37.

Berhane, G., D. O. Gilligan, J. Hoddinott, N. Kumar, and A. S. Taffesse (2014). Can social protection work in africa? the impact of Ethiopias Productive Safety Net Programme. Economic Development and Cultural Change 63(1), 1-26. 
Camfield, L. (2014). Growing up in ethiopia and andhra pradesh: The impact of social protection schemes on girls roles and responsibilities. European Journal of Development Research 26(1), 107-123.

Christian, K., F. J. Morrison, J. A. Frazier, and G. Massetti (2009). Specificity in the nature and timing of cognitive growth in kindergarten and first grade. Journal of Cognition and Development 1(4), 429-448.

Cueto, S. and J. Leon (2012). Psychometric characteristics of cognitive development and achievement instruments in round 2 of young lives. Young Lives Technical Note (25).

Cueto, S., J. Leon, G. Guerrero, and I. Munoz (2009). Psychometric characteristics of cognitive development and achievement instruments in round 2 of young lives. Young Lives Technical Note (15).

Cunha, F. and J. J. Heckman (2007). The technology of skill formation. American Economic Review 97(2), 31-47.

Cunha, F. and J. J. Heckman (2008). Formulating, identifying and estimating the technology of cognitive and noncognitive skill formation. Journal of human resources 43(4), 738-782.

Das, J., S. Dercon, J. Habyarimana, P. Krishnan, K. Muralidharan, and V. Sundararaman (2013). School inputs, household substitution, and test scores. American Economic Journal: Applied Economics 5(2), 29-57.

Dercon, S. and C. Porter (2014). Live aid revisited: long term impacts of the 1984 ethiopian famine on children. Journal of the European Economic Association 12(4), $927-948$.

Dunn, L. M. and L. M. Dunn (1997). Examiners manual for the ppvt-iii. form iiia and iiib. Technical report, Minnesota: AGS. 
Emirie, G., W. Negatu, and D. Getachew (2009). Impacts of productive safety net programme on child poverty reduction: Implications for child education. Young Lives IDRC Paper.

Fernald, L. C., P. J. Gertler, and L. M. Neufeld (2008a). Role of cash in conditional cash transfer programmes for child health, growth, and development: an analysis of Mexico's Oportunidades. The Lancet 371(9615), 828-837.

Fernald, L. C., P. J. Gertler, and L. M. Neufeld (2008b). Role of cash in conditional cash transfer programmes for child health, growth, and development: an analysis of mexico's oportunidades. The Lancet 371(9615), 828-837.

Fiorini, M. and M. P. Keane (2014). How the allocation of childrens time affects cognitive and noncognitive development. Journal of Labor Economics 32(4), 787-836.

Gertler, P. (2004). Do conditional cash transfers improve child health? Evidence from PROGRESA's control randomized experiment. American Economic Review, 336-341.

Glewwe, P. and E. A. Miguel (2007). The impact of child health and nutrition on education in less developed countries. Handbook of Development Economics 4, 35613606.

Glewwe, P. and K. Muralidharan (2016). Improving school education outcomes in developing countries: Evidence, knowledge gaps, and policy implications. In Handbook of Economics of Education, Volume 5, pp. 653-743. North Holland.

Hoddinott, J. (2014). Operationalizing graduation in Ethiopias Productive Safety Net Program. In Graduation and Social Protection Conference. IDS.

Hoddinott, J.and Maluccio, J., J. Behrman, R. Flores, and R. Martorell (2008). Effect of a nutrition intervention during early childhood on economic productivity in guatemalan adults. Lancet 371 (9610, 2 Feb), 411-416. 
Holmemo, C. (2014). Project information document (appraisal stage) - et productive safety nets 4 program (psnp 4) - p146883. Technical report.

Leon, J. and A. Singh (2017). Equating test scores for receptive vocabulary across rounds and cohorts in ethiopia, india and vietnam. Young Lives Technical Note (40).

Macours, K., N. Schady, and R. Vakis (2012). Cash transfers, behavioral changes, and cognitive development in early childhood: Evidence from a randomized experiment. American Economic Journal: Applied Economics 4 (2), 247-273.

Mani, S., J. R. Behrman, S. Galab, and P. Reddy (2014). Impact of the nregs on schooling and intellectual human capital. GCC Working Paper Series (1-10).

Ministry of Agriculture and Rural Development (2004). Productive safety net targeting guideline. Ethiopia: MoARD, food security coordination bureau. Technical report.

Paxson, C. and N. Schady (2010). Does money matter? the effects of cash transfers on child development in rural ecuador. Economic development and cultural change 59(1), $187-229$.

Porter, C. and R. Goyal (2014). Social protection as child protection. mimeo.

Save the Children UK (2008). Cash, food payments and risk: A review of the productive safety net programme. Technical report, London: Save the Children UK.

Shah, M. and B. M. Steinberg (2015). Workfare and human capital investment: Evidence from india. Technical report, National Bureau of Economic Research.

Subbarao, K., C. Del Ninno, C. Andrews, and C. Rodríguez-Alas (2012). Public works as a safety net: design, evidence, and implementation. World Bank Publications. 
Tafere, Y. and T. Woldehanna (2012). Beyond food security: Transforming the productive safety net programme in ethiopia for the well-being of children. Young Lives Working Paper 83.

Todd, P. E. and K. I. Wolpin (2003). On the specification and estimation of the production function for cognitive achievement. The Economic Journal 113(485), F3-F33.

Todd, P. E. and K. I. Wolpin (2007). The production of cognitive achievement in children: Home, school, and racial test score gaps. Journal of Human capital 1(1), 91-136.

USAID (2012). Ethiopia's productive safety net and household asset building programs (2006-2010) a synthesis of findings. Technical report, USAID.

Woldehanna, T. (2010). Productive safety net program and childrens time use between work and schooling in ethiopia. In Child Welfare in Developing Countries, pp. 157-209. Springer.

Yablonski, J. (2007). Children and social protection: Towards a package that works. Technical report, London: SCUK. 


\section{$\begin{array}{ll}7 & \text { Tables }\end{array}$}

Figure 1: PSNP and survey timing

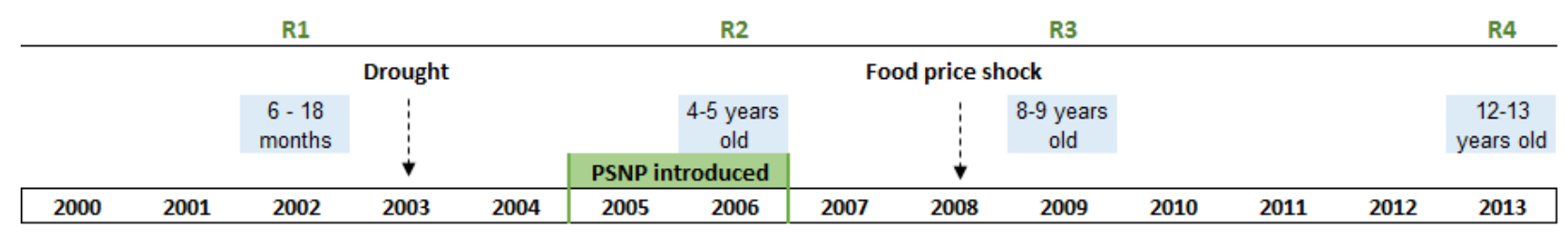


Table 1: Descriptive statistics

\begin{tabular}{|c|c|c|c|}
\hline & Mean & Std. Error & $\mathrm{N}$ \\
\hline \multicolumn{4}{|l|}{ Cognitive skills } \\
\hline PPVT (IRT, R4) & 1.69 & $(1.228)$ & 822 \\
\hline PPVT (IRT, R2) & -0.26 & $(0.951)$ & 760 \\
\hline Math (z-score, R4) & 0.01 & $(1.005)$ & 947 \\
\hline Math (z-score, R2) & 0.01 & $(1.011)$ & 947 \\
\hline \multicolumn{4}{|l|}{ Socio-economic status } \\
\hline Wealth Index (R2) : bottom tercile & 0.51 & $(0.500)$ & 947 \\
\hline Wealth Index (R2): mid tercile & 0.37 & $(0.484)$ & 947 \\
\hline Wealth Index (R2): top tercile & 0.12 & $(0.327)$ & 947 \\
\hline Mother's education: primary and above & 0.44 & $(0.497)$ & 947 \\
\hline \multicolumn{4}{|l|}{ Demographics } \\
\hline Male & 0.55 & $(0.498)$ & 947 \\
\hline Age (in months) at R4 & 145.87 & $(3.916)$ & 947 \\
\hline \multicolumn{4}{|l|}{ Shocks in R3 } \\
\hline Drought & 0.49 & $(0.500)$ & 947 \\
\hline Flood & 0.19 & $(0.396)$ & 947 \\
\hline Crop Failure & 0.38 & $(0.486)$ & 947 \\
\hline Illness of household member & 0.46 & $(0.499)$ & 947 \\
\hline Death of father & 0.04 & $(0.194)$ & 947 \\
\hline Death of mother & 0.03 & $(0.181)$ & 947 \\
\hline Number of shocks & 1.85 & $(1.357)$ & 947 \\
\hline \multicolumn{4}{|l|}{ Shocks in R4 } \\
\hline Drought & 0.20 & $(0.397)$ & 947 \\
\hline Flood & 0.10 & $(0.299)$ & 947 \\
\hline Crop Failure & 0.26 & $(0.440)$ & 947 \\
\hline Illness of household member & 0.19 & $(0.392)$ & 947 \\
\hline Number of shocks & 0.83 & $(1.086)$ & 947 \\
\hline \multicolumn{4}{|l|}{ Time use (Hours spent on) (R4) } \\
\hline Working & 4.80 & $(1.867)$ & 947 \\
\hline Schooling & 5.71 & $(1.795)$ & 947 \\
\hline Studying outside school & 1.40 & $(0.836)$ & 947 \\
\hline \multicolumn{4}{|l|}{ Expenditures (R4) } \\
\hline Food expenditure & 295.54 & $(161.150)$ & 947 \\
\hline Non-food expenditure & 151.68 & $(193.645)$ & 947 \\
\hline$\%$ expenditure on education & 0.01 & $(0.015)$ & 947 \\
\hline \multicolumn{4}{|l|}{ Aspirations and non-cognitive skills } \\
\hline Caregiver's educational aspiration (R3) & 0.74 & $(0.439)$ & 947 \\
\hline Agency Index (R4) & 0.01 & $(0.541)$ & 947 \\
\hline Pride Index (R4) & -0.04 & $(0.689)$ & 947 \\
\hline
\end{tabular}


Table 2: PSNP Beneficiaries

\begin{tabular}{lll}
\hline PSNP Groups & Obs & Percentage \\
\hline Non-beneficiaries & $561(190)$ & $59.2 \%(33.0 \%)$ \\
2009 PSNP only & 140 & $14.8 \%(24.3 \%)$ \\
2009 \& 2013 PSNP & 246 & $25.9 \%(42.7 \%)$ \\
\hline Total & $947(576)$ & $100.0 \%$ \\
\hline
\end{tabular}

Notes: Regression sample only. Numbers in parentheses represent the restricted sample as outlined in the text in section 4.1 .

Table 3: Control and Treatment groups: baseline characteristics (using broad control group)



Note: All variables are measured at round 2 (2006). Average values; standard deviation reported in parentheses. The PPVT score reported is the MLE from the IRT models. Math score is the math test raw score standardized within the sample.The p-values for a t-test for differences in means between control group and the PSNP groups are reported in the last two columns. "Working" is defined as the sum of hours spent caring for household members, house chores, unpaid work and paid work. 
Table 4: Control and Treatment groups: baseline characteristics (using restricted control group)

\begin{tabular}{|c|c|c|c|c|c|c|c|c|}
\hline & & & \multirow{3}{*}{\multicolumn{2}{|c|}{$\begin{array}{c}2009 \text { only } \\
\text { PSNP }\end{array}$}} & \multirow{3}{*}{\multicolumn{2}{|c|}{$\begin{array}{l}2009 \& 2013 \\
\text { PSNP }\end{array}$}} & \multicolumn{2}{|c|}{ T-tests } \\
\hline & \multirow{2}{*}{\multicolumn{2}{|c|}{ Control }} & & & & & \multirow{3}{*}{$\begin{array}{c}\text { C-2009 } \\
\text { PSNP } \\
\text { p-value }\end{array}$} & \multirow{3}{*}{$\begin{array}{c}\text { C-2009\&13 } \\
\text { PSNP } \\
\text { p-value }\end{array}$} \\
\hline & & & & & & & & \\
\hline & Mean & Std.Dev & Mean & Std.Dev & Mean & Std.Dev & & \\
\hline Math (z-score) & 0.12 & 0.068 & 0.01 & 0.089 & -0.10 & 0.063 & 0.299 & 0.020 \\
\hline PPVT (IRT) & -0.28 & 0.079 & -0.37 & 0.085 & -0.32 & 0.062 & 0.436 & 0.722 \\
\hline HAZ & -1.56 & 0.070 & -1.47 & 0.075 & -1.65 & 0.068 & 0.381 & 0.377 \\
\hline \multicolumn{9}{|l|}{ Mother's educ.: } \\
\hline$\geq$ primary & 0.36 & 0.035 & 0.21 & 0.035 & 0.26 & 0.028 & 0.005 & 0.030 \\
\hline Household size & 6.20 & 0.142 & 6.55 & 0.159 & 6.09 & 0.122 & 0.105 & 0.569 \\
\hline \multicolumn{9}{|l|}{ Wealth Index } \\
\hline Bottom tercile & 0.52 & 0.036 & 0.59 & 0.042 & 0.57 & 0.032 & 0.196 & 0.279 \\
\hline Mid tercile & 0.37 & 0.035 & 0.36 & 0.041 & 0.34 & 0.030 & 0.862 & 0.433 \\
\hline Top tercile & 0.11 & 0.022 & 0.04 & 0.017 & 0.09 & 0.018 & 0.038 & 0.580 \\
\hline \multicolumn{9}{|l|}{ Expenditure } \\
\hline Food expenditure & 85.22 & 4.439 & 81.18 & 5.759 & 78.22 & 3.792 & 0.572 & 0.229 \\
\hline Non-food expenditure & 33.38 & 2.033 & 25.09 & 1.647 & 27.97 & 1.390 & 0.003 & 0.024 \\
\hline $\begin{array}{l}\% \text { expenditure on educ. } \\
\text { Time use (hours) }\end{array}$ & 0.01 & 0.001 & 0.01 & 0.001 & 0.01 & 0.001 & 0.709 & 0.448 \\
\hline Working & 2.68 & 0.246 & 2.91 & 0.342 & 2.40 & 0.227 & 0.579 & 0.414 \\
\hline Schooling & 0.96 & 0.146 & 0.61 & 0.074 & 0.77 & 0.096 & 0.071 & 0.259 \\
\hline Studying outside school & 0.08 & 0.029 & 0.01 & 0.012 & 0.03 & 0.014 & 0.079 & 0.138 \\
\hline
\end{tabular}

Note: All variables are measured at round 2 (2006). Average values; standard deviation reported in parentheses. The PPVT score reported is the MLE from the IRT models. Math score is the math test raw score standardized within the sample. The p-values for a t-test for differences in means between control group and the PSNP groups are reported in the last two columns. "Working" is defined as the sum of hours spent caring for household members, house chores, unpaid work and paid work. 
Table 5: PSNP Impact on Maths scores at age 12

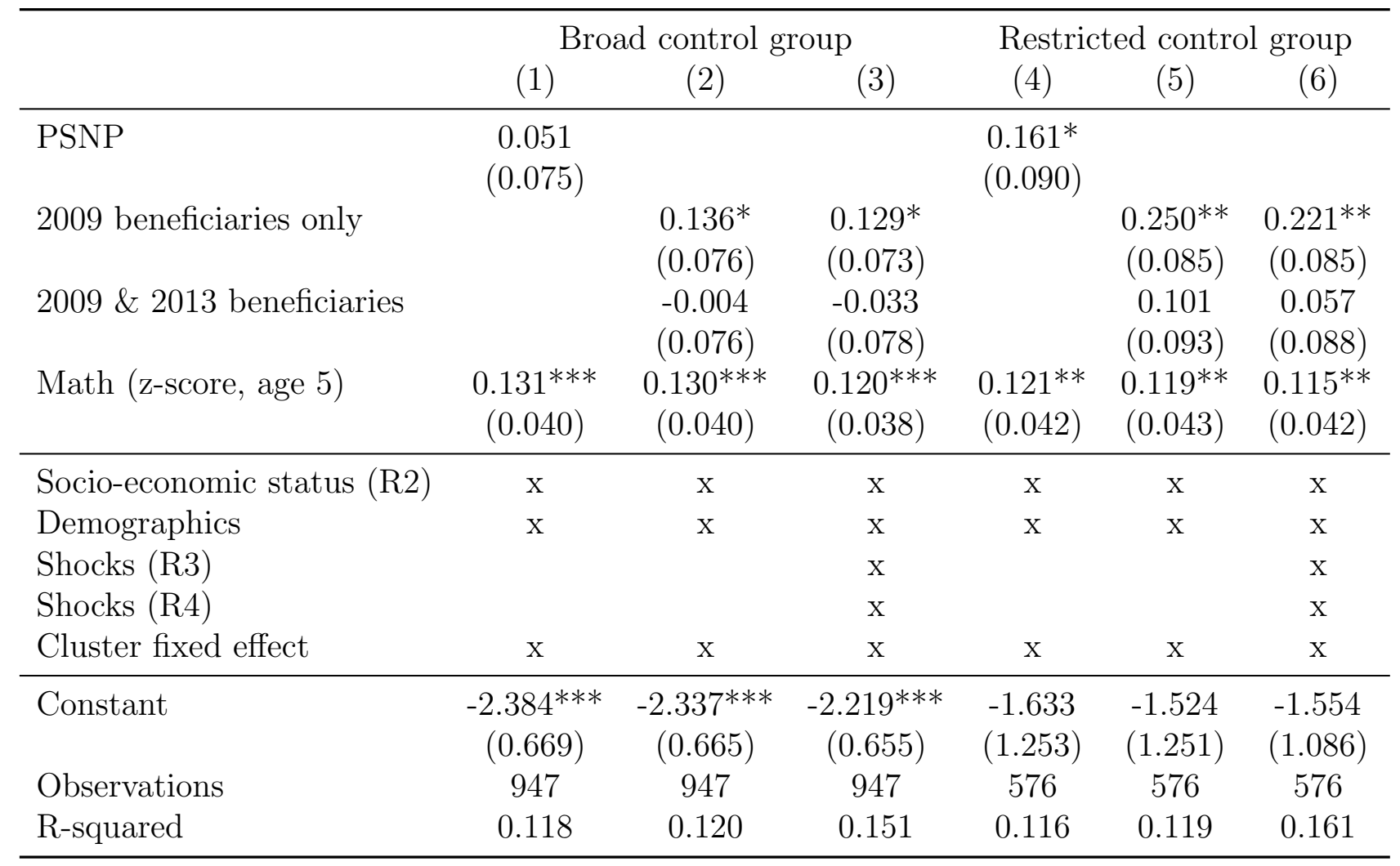

Note: The table reports the OLS estimates with standard errors (reported in parentheses) clustered at village level. ${ }^{*} \mathrm{p}<0.1 * * \mathrm{p}<0.05 * * * \mathrm{p}<0.01$. The dependent variable is maths test score measured at the age of 12 and standardized within the sample by age (round). All controls are included as specified. Columns (1)-(3) sample includes the broad control group; columns (4)-(6) the restricted control group. 
Table 6: PSNP Impact on Language scores at age 12

\begin{tabular}{|c|c|c|c|c|c|c|}
\hline & \multicolumn{3}{|c|}{ Broad control group } & \multicolumn{3}{|c|}{ Restricted control group } \\
\hline & $(1)$ & $(2)$ & $(3)$ & $(4)$ & $(5)$ & $(6)$ \\
\hline PSNP & $\begin{array}{c}0.025 \\
(0.074)\end{array}$ & & & $\begin{array}{c}0.103 \\
(0.091)\end{array}$ & & \\
\hline 2009 beneficiaries only & & $\begin{array}{c}0.048 \\
(0.095)\end{array}$ & $\begin{array}{c}0.072 \\
(0.095)\end{array}$ & & $\begin{array}{c}0.130 \\
(0.115)\end{array}$ & $\begin{array}{c}0.069 \\
(0.120)\end{array}$ \\
\hline 2009 \& 2013 beneficiaries & & $\begin{array}{c}0.014 \\
(0.087)\end{array}$ & $\begin{array}{c}0.041 \\
(0.059)\end{array}$ & & $\begin{array}{c}0.089 \\
(0.098)\end{array}$ & $\begin{array}{c}0.027 \\
(0.081)\end{array}$ \\
\hline PPVT (IRT, R2) & $\begin{array}{c}0.171^{* * * *} \\
(0.041)\end{array}$ & $\begin{array}{c}0.171^{* * *} \\
(0.042)\end{array}$ & $\begin{array}{c}0.148^{* * *} \\
(0.038)\end{array}$ & $\begin{array}{c}0.148^{* * *} \\
(0.041)\end{array}$ & $\begin{array}{c}0.148^{* * *} \\
(0.041)\end{array}$ & $\begin{array}{c}0.143^{* * *} \\
(0.042)\end{array}$ \\
\hline Socio-economic status (R2) & $\mathrm{x}$ & $\mathrm{x}$ & $\mathrm{x}$ & $\mathrm{x}$ & $\mathrm{x}$ & $\mathrm{x}$ \\
\hline Demographics & $\mathrm{x}$ & $\mathrm{x}$ & $\mathrm{x}$ & $\mathrm{x}$ & $\mathrm{x}$ & $\mathrm{x}$ \\
\hline Shocks (R3) & & & $\mathrm{x}$ & & & $\mathrm{x}$ \\
\hline Shocks (R4) & & & $\mathrm{x}$ & & & $\mathrm{x}$ \\
\hline Language & $\mathrm{x}$ & $\mathrm{x}$ & $\mathrm{x}$ & $\mathrm{x}$ & $\mathrm{x}$ & $\mathrm{x}$ \\
\hline Constant & $\begin{array}{l}-1.655 \\
(1.137)\end{array}$ & $\begin{array}{l}-1.630 \\
(1.140)\end{array}$ & $\begin{array}{c}-0.684 \\
(1.093)\end{array}$ & $\begin{array}{l}-1.255 \\
(1.642)\end{array}$ & $\begin{array}{l}-1.212 \\
(1.641)\end{array}$ & $\begin{array}{c}-0.541 \\
(1.364)\end{array}$ \\
\hline Observations & 824 & 824 & 824 & 568 & 568 & 568 \\
\hline R-squared & 0.265 & 0.266 & 0.326 & 0.242 & 0.242 & 0.331 \\
\hline
\end{tabular}

Note: The table reports the OLS estimates with standard errors (reported in parentheses) clustered at village level. ${ }^{*} \mathrm{p}<0.1{ }^{* *} \mathrm{p}<0.05^{* * *} \mathrm{p}<0.01$. The dependent variable is the PPVT score measured at the age of 12 and standardized within the sample using Item Response Theory (Leon and Singh, 2017). All controls are included as specified. Columns (1)-(3) sample includes the broad control group; columns (4)-(6) the restricted control group. 
Table 7: Mechanisms (using restricted control group)

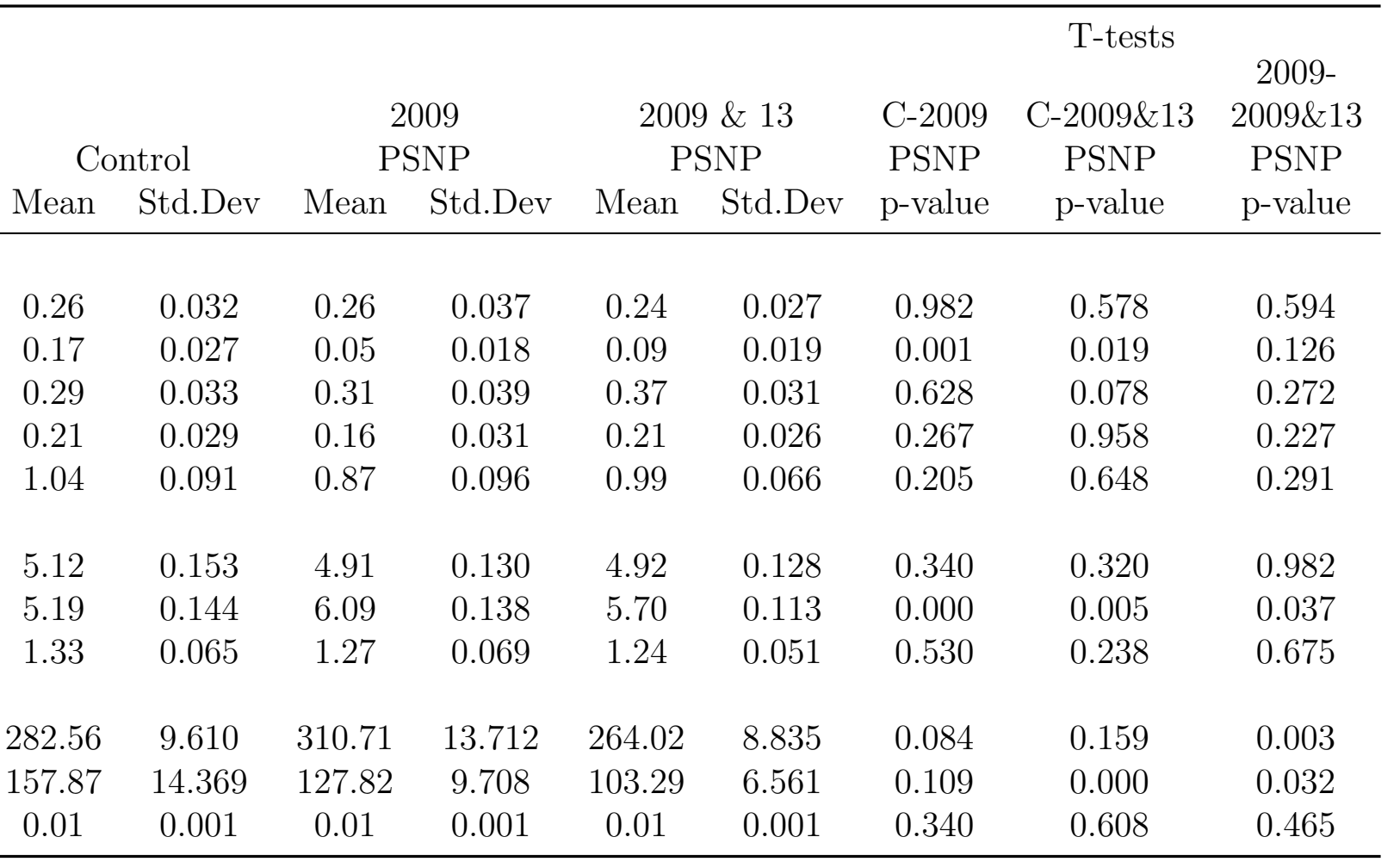

Note: All variables are measured in round 4. "Working" is defined as the sum of hours spent caring for household members, house chores, unpaid work and paid work. 


\section{Appendix}

Table A.1: Descriptive statistics: using the restricted control group

\begin{tabular}{|c|c|c|c|}
\hline & Mean & Std. Error & $\mathrm{N}$ \\
\hline \multicolumn{4}{|l|}{ Cognitive skills } \\
\hline PPVT (R4) & 1.67 & $(1.131)$ & 521 \\
\hline PPVT (R2) & -0.32 & $(0.958)$ & 514 \\
\hline Math (R4) & -0.07 & $(0.952)$ & 576 \\
\hline Math (R2) & 0.00 & $(0.990)$ & 576 \\
\hline \multicolumn{4}{|l|}{ Socio-economic status } \\
\hline Wealth Index (R2): bottom tercile & 0.56 & $(0.497)$ & 576 \\
\hline Wealth Index (R2): mid tercile & 0.36 & $(0.479)$ & 576 \\
\hline Wealth Index (R2): top tercile & 0.08 & $(0.277)$ & 576 \\
\hline Mother's education: primary and above & 0.41 & $(0.492)$ & 576 \\
\hline \multicolumn{4}{|l|}{ Demographics } \\
\hline Male & 0.54 & $(0.499)$ & 576 \\
\hline Age (in months) at R4 & 145.48 & $(4.030)$ & 576 \\
\hline \multicolumn{4}{|l|}{ Shocks in R3 } \\
\hline Drought & 0.59 & $(0.493)$ & 576 \\
\hline Flood & 0.20 & $(0.401)$ & 576 \\
\hline Crop Failure & 0.47 & $(0.499)$ & 576 \\
\hline Illness of household member & 0.44 & $(0.497)$ & 576 \\
\hline Death of father & 0.04 & $(0.196)$ & 576 \\
\hline Death of mother & 0.04 & $(0.200)$ & 576 \\
\hline Number of shocks & 2.01 & $(1.334)$ & 576 \\
\hline \multicolumn{4}{|l|}{ Shocks in R4 } \\
\hline Drought & 0.25 & $(0.435)$ & 576 \\
\hline Flood & 0.11 & $(0.310)$ & 576 \\
\hline Crop Failure & 0.33 & $(0.471)$ & 576 \\
\hline Illness of household member & 0.19 & $(0.396)$ & 576 \\
\hline Number of shocks & 0.98 & $(1.137)$ & 576 \\
\hline \multicolumn{4}{|l|}{ Time use (Hours spent on) (R4) } \\
\hline Working & 4.98 & $(1.939)$ & 576 \\
\hline Schooling & 5.63 & $(1.848)$ & 576 \\
\hline Studying outside school & 1.28 & $(0.833)$ & 576 \\
\hline \multicolumn{4}{|l|}{ Expenditures (R4) } \\
\hline Food expenditure & 281.49 & $(143.709)$ & 576 \\
\hline Non-food expenditure & 127.26 & $(145.435)$ & 576 \\
\hline$\%$ expenditure on education & 0.01 & $(0.015)$ & 576 \\
\hline \multicolumn{4}{|l|}{ Aspirations and non-cognitive skills } \\
\hline Caregiver's educational aspiration (R3) & 0.72 & $(0.450)$ & 576 \\
\hline Agency Index (R4) & 0.01 & $(0.572)$ & 576 \\
\hline Pride Index (R4) & -0.04 & $(0.707)$ & 576 \\
\hline
\end{tabular}

